\title{
OPEN Effects of whole blood storage in a polyolefin blood bag on platelets for acute normovolemic hemodilution
}

\author{
Yutaka Murata $^{1,2}$, Eriko Kusudo ${ }^{1,2}$, Shuji Kawamoto ${ }^{1 \bowtie}$ \& Kazuhiko Fukuda ${ }^{1}$
}

Acute normovolemic hemodilution (ANH) is a potential transfusion method for platelets, as well as for red blood cells. However, previous studies have shown that whole blood storage in ANH decreases platelet aggregability by $14.7-76.3 \%$ and that this decrease is not recovered by reinfusion. We investigated whether a new whole blood storage method for $6 \mathrm{~h}$ using a polyolefin bag, based on the platelet concentrates storage method, would maintain platelet function better than the conventional method using a polyvinyl chloride bag. We demonstrated that storage of whole blood in a polyolefin bag maintained ADP-induced aggregation rates at more than twofold higher than those in a polyvinyl chloride bag, and also significantly suppressed P-selectin expression, a platelet activation marker (ADP-induced aggregation rates: $24.6 \pm 5.1 \%$ vs. $51.7 \pm 11.5 \%, p=0.002$; P-selectin expression; $50.3 \pm 8.4 \mathrm{MFI}$ vs. $31.6 \pm 9.3 \mathrm{MFI}, \mathrm{p}=0.018$ ). These results could be attributed to the high gas permeability of polyolefin, which lowered $\mathrm{PCO}_{2}$ and maintained a high pH with or without agitation. There were no significant changes in platelet count and red blood cell parameters due to the storage methods. Our results suggest that ANH using polyolefin bags is advantageous in improving hemostatic function compared to the conventional method.

Allogeneic blood transfusion is a common treatment for perioperative hemorrhage. Cardiac surgeries use large amounts of blood products, which consume $10-15 \%$ of the U.S. blood supply ${ }^{1}$. However, even small amounts of allogeneic blood transfusion increase mortality and serious complications ${ }^{2}$. For this reason and the global shortage of blood products ${ }^{3,4}$, use of allogeneic transfusion needs to be reduced.

Acute normovolemic hemodilution (ANH) is a simple and low-cost transfusion method that may be an alternative option to allogeneic transfusion ${ }^{1}$. In ANH, $400-1200 \mathrm{~mL}$ of whole blood is removed from the patient immediately prior to an operation. The removed blood is mixed with CPDA solution and is stored without agitation at room temperature at the bedside. The circulating blood of the patient is diluted by crystalloid or colloid solutions, which reduces blood loss during surgery. At the conclusion of the operation, the stored autologous blood is restored to the patient (Fig. 1). ANH is safer than allogeneic blood transfusion because it does not cause graft-versus-host disease, infection or transfusion-related acute lung injury ${ }^{1}$. ANH has been covered by a national health insurance in Japan since 2016. Previous reports have shown that ANH substantially reduces intraoperative blood loss and allogeneic blood transfusion ${ }^{1,5,6}$.

ANH also reduces platelet and plasma transfusion significantly in cardiac surgeries ${ }^{7}$. Platelets of patients during cardiac surgeries are activated and consumed by cardiopulmonary bypass $(\mathrm{CPB})^{8}$ through mechanisms of bypass- and heparin-induced activation, lack of extrinsic stimulating factors, and exposure to hypothermia during bypass ${ }^{9}$. Kotake et al. ${ }^{10}$ showed that post-CPB platelet counts and ADP-induced aggregability decrease to $57 \%$ and $10 \%$ of the respective preoperative values. ANH avoids potential platelet damage in CPB and can provide "fresh" platelets ${ }^{8}$. If ANH provides platelets with adequate hemostatic function, it can contribute to reduction in blood loss and allogeneic transfusion volume after CPB. However, several studies have found that the conventional method of ANH severely impairs platelet aggregability assessed by whole blood aggregometry, multiple electrode aggregometry, and impedance aggregometry (14.7-76.3\% compared to pre-surgery) and that the function does not recover after transfusion ${ }^{11-14}$ (Fig. 1). Therefore, there is a need to develop a new ANH method with a high hemostatic effect by maintaining high platelet function in surgeries, including cardiac surgeries, in which massive bleeding can occur.

\footnotetext{
${ }^{1}$ Department of Anesthesia, Kyoto University Hospital, 54 Shogoin Kawahara-cho, Sakyo-ku, Kyoto 606-8507, Japan.

${ }^{2}$ These authors contributed equally: Yutaka Murata and Eriko Kusudo. ${ }^{\varpi}$ email: skawamot@kuhp.kyoto-u.ac.jp
} 


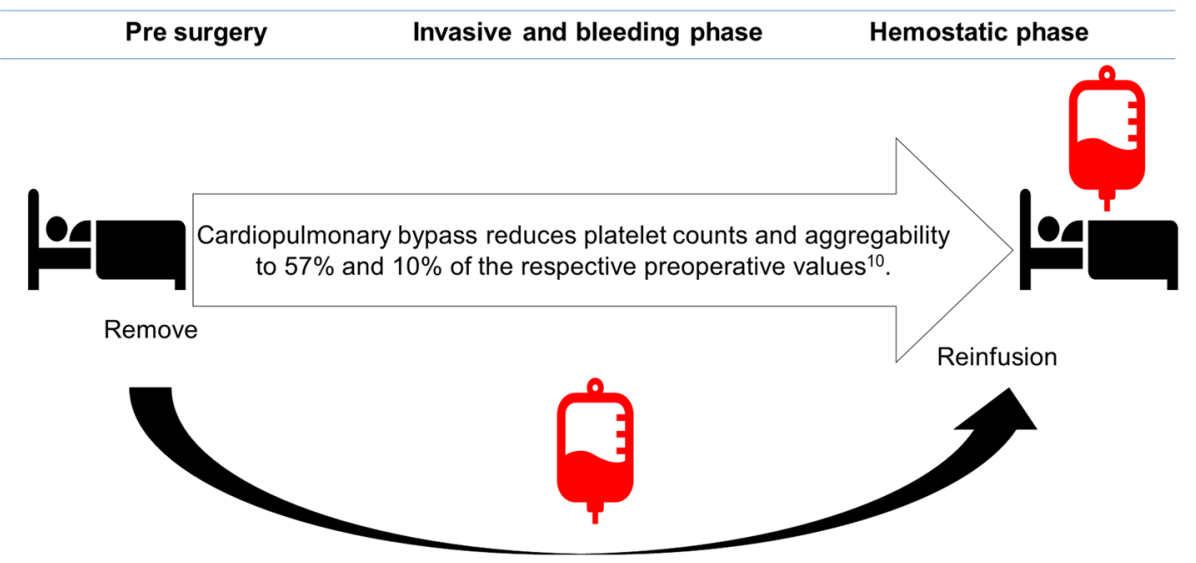

ANH also reduces platelet aggregability to $14.7-76.3 \%$ permanently ${ }^{11-14}$.

Figure 1. The conventional method of ANH cannot maintain platelet function. Cardiopulmonary bypass reduces platelet counts and function decreases to $57 \%$ and $10 \%$ of the respective preoperative values ${ }^{10}$. ANH also markedly reduces platelet function and these changes do not recover after transfusion ${ }^{11-14}$. This figure was drawn using Microsoft PowerPoint 2016 (Ver. 2103, https://www.microsoft.com/ja-jp/microsoft-365/power point).

\begin{tabular}{|l|l|l|l|l|}
\hline & Allogenic RBC & PABD & ANH & Platelet concentrates \\
\hline Temperature & $2-6^{\circ} \mathrm{C}$ & $2-6^{\circ} \mathrm{C}$ & Room temperature & $20-24^{\circ} \mathrm{C}$ \\
\hline Container & PVC bag & PVC bag & PVC bag & Polyolefin bag \\
\hline Agitation & At rest & At rest & At rest & Agitation $(60 \mathrm{rpm})$ \\
\hline Solution & CPD $\cdot \mathrm{MAP}$ & CPDA & CPDA & ACD-A \\
\hline Expiration date & 21 days & 35 days & Several hours & 4 days \\
\hline
\end{tabular}

Table 1. Blood storage conditions and expiration dates. Blood storage conditions and expiration dates vary by country and facility. This table refers to some guidelines and our practice ${ }^{1,15-23} \cdot R B C$ red blood cell, $P A B D$ preoperative autologous blood donation, $C P D-M A P$ citrate-phosphate-dextrose-mannitol-adeninephosphate, $C P D A$ citrate-phosphate-dextrose-adenine, $A C D$ - $A$ acid-citrate-dextrose formula A.

The storage conditions and expiration date of each blood production are shown in Table $1^{1,15-23}$. The major differences in storage for ANH and platelet concentrates are the bag material and use of agitation. Few studies mention the material of the storage bags used for $\mathrm{ANH}$, but polyvinyl chloride (PVC) storage bags for red blood cells are generally used because of their excellent durability despite their low gas permeability $1,8,13,16,19,21$. In contrast, platelet concentrates are stored with agitation in bags made of highly oxygen-permeable materials such as polyolefin ${ }^{16,22}$, which provide sufficient oxygen for platelets to maintain aerobic respiration and ensure gas exchange between the storage medium and the atmosphere ${ }^{24}$.

We hypothesized that use of a PVC bag at rest is responsible for the significant reduction in platelet function in conventional ANH. Therefore, we examined if whole blood storage in a polyolefin bag with or without agitation could maintain platelet function more effectively than that achieved by the conventional method.

\section{Results}

The results are shown in Table 2 and Fig. 2 (see "Methods" for the storage groups). First, the pH of venous blood mixed with CPDA before $6 \mathrm{~h}$ storage was lower than the normal venous blood $\mathrm{pH}(7.31-7.41)^{25}$ (Table 2 PRE). Compared to PRE, $\mathrm{pH}$ and ADP-induced platelet aggregation rates in PVN storage decreased significantly, and lactate and P-selectin increased significantly (Table 2 and Fig. 2 PRE-PVN). These results show that whole blood stored in the conventional ANH method severely impairs platelet function, as previous studies have shown ${ }^{11-14}$ (Fig. 1). In contrast, whole blood storage in polyolefin bags maintained significantly higher $\mathrm{pH}$ and ADP-induced platelet aggregation rates and significantly lower $\mathrm{PCO}_{2}$ and $\mathrm{P}$-selectin, compared to those in the PVN group (Table 2 and Fig. 2 PON-PVN). $\mathrm{PO}_{2}$ in the PON group was relatively high, but not significantly higher than in the PVN group. No parameters in the PVA group differed significantly from those in the PVN group, and the POA and PON group showed significant differences from PVN in the same parameters. There were no significant changes in platelet count, mean platelet volume, and red blood cell parameters among all groups. 


\begin{tabular}{|c|c|c|c|c|c|c|c|c|c|}
\hline \multirow[b]{2}{*}{ Item } & \multirow[b]{2}{*}{ PRE } & \multirow[b]{2}{*}{ PVN } & \multirow[b]{2}{*}{ PVA } & \multirow[b]{2}{*}{ PON } & \multirow[b]{2}{*}{ POA } & \multicolumn{4}{|c|}{$\mathrm{P}$ value $\left({ }^{\star} \mathrm{P}<0.05\right)$} \\
\hline & & & & & & PRE-PVN & PVA-PVN & PON-PVN & POA-PVN \\
\hline $\begin{array}{l}\text { Platelet } \\
\text { count }\left(10^{4} /\right. \\
\mu \mathrm{L})\end{array}$ & $17.1(2.7)$ & $17.4(3.2)$ & $16.8(3.5)$ & $16.9(3.1)$ & $17.4(2.5)$ & 1.000 & 0.994 & 0.998 & 1.000 \\
\hline $\begin{array}{l}\text { Hemoglobin } \\
(\mathrm{g} / \mathrm{dL})\end{array}$ & $13.0(1.2)$ & $12.8(1.2)$ & $12.1(0.8)$ & $13.4(1.0)$ & $13.1(1.1)$ & 0.995 & 0.689 & 0.706 & 0.976 \\
\hline $\begin{array}{l}\text { Hematocrit } \\
(\%)\end{array}$ & $37.6(3.2)$ & $36.6(3.1)$ & $34.5(2.9)$ & $38.7(2.5)$ & $37.5(3.5)$ & 0.965 & 0.603 & 0.652 & 0.973 \\
\hline $\begin{array}{l}\text { Mean cor- } \\
\text { puscular } \\
\text { volume (fL) }\end{array}$ & $88.5(1.6)$ & $88.6(1.5)$ & $88.3(1.8)$ & $88.5(1.5)$ & $88.3(1.4)$ & 1.000 & 0.997 & 1.000 & 0.994 \\
\hline $\begin{array}{l}\text { Mean plate- } \\
\text { let volume } \\
\text { (fL) }\end{array}$ & $8.0(0.3)$ & $8.1(0.3)$ & $8.1(0.3)$ & $8.2(0.2)$ & $8.2(0.3)$ & 0.828 & 1.000 & 0.918 & 0.918 \\
\hline $\mathrm{pH}$ & \begin{tabular}{|l|}
7.038 \\
$(0.102)$ \\
\end{tabular} & \begin{tabular}{|l|}
6.919 \\
$(0.035)$ \\
\end{tabular} & \begin{tabular}{|l|}
6.912 \\
$(0.071)$ \\
\end{tabular} & \begin{tabular}{|l|}
7.053 \\
$(0.063)$ \\
\end{tabular} & \begin{tabular}{|l|}
7.029 \\
$(0.024)$ \\
\end{tabular} & $0.011^{*}$ & 0.999 & $0.004^{*}$ & $0.020^{*}$ \\
\hline $\begin{array}{l}\mathrm{PCO}_{2} \\
(\mathrm{mmHg})\end{array}$ & $71.2(13.0)$ & $81.3(11.0)$ & $81.6(11.6)$ & $64.2(1.5)$ & $63.6(6.5)$ & $0.348^{*}$ & 1.000 & $0.045^{*}$ & $0.037^{\star}$ \\
\hline $\begin{array}{l}\mathrm{PO}_{2} \\
(\mathrm{mmHg})\end{array}$ & $46.1(23.9)$ & $49.7(23.2)$ & $54.3(26.0)$ & $62.4(35.0)$ & $64.3(35.7)$ & 0.999 & 0.997 & 0.901 & 0.850 \\
\hline $\begin{array}{l}\begin{array}{l}\mathrm{HCO}_{3} \text { act } \\
(\mathrm{mM})\end{array} \\
\end{array}$ & $18.7(3.4)$ & $16.2(1.7)$ & $15.8(1.8)$ & $17.6(2.5)$ & $16.4(1.9)$ & 0.260 & 0.994 & 0.756 & 1.000 \\
\hline $\begin{array}{l}\text { Lactate }(\mathrm{mg} / \\
\mathrm{dL})\end{array}$ & $14.1(8.2)$ & $24.3(5.7)$ & $23.5(5.0)$ & $26.0(6.0)$ & $25.2(5.1)$ & $0.024^{\star}$ & 0.998 & 0.965 & 0.997 \\
\hline
\end{tabular}

Table 2. Results for complete blood count and blood gas analysis in different storage conditions. Data are expressed as mean (SD). $\mathrm{N}=6 .{ }^{\star} \mathrm{P}<0.05$ vs. PVN by one-way ANOVA with a Dunnett multiple comparison test.

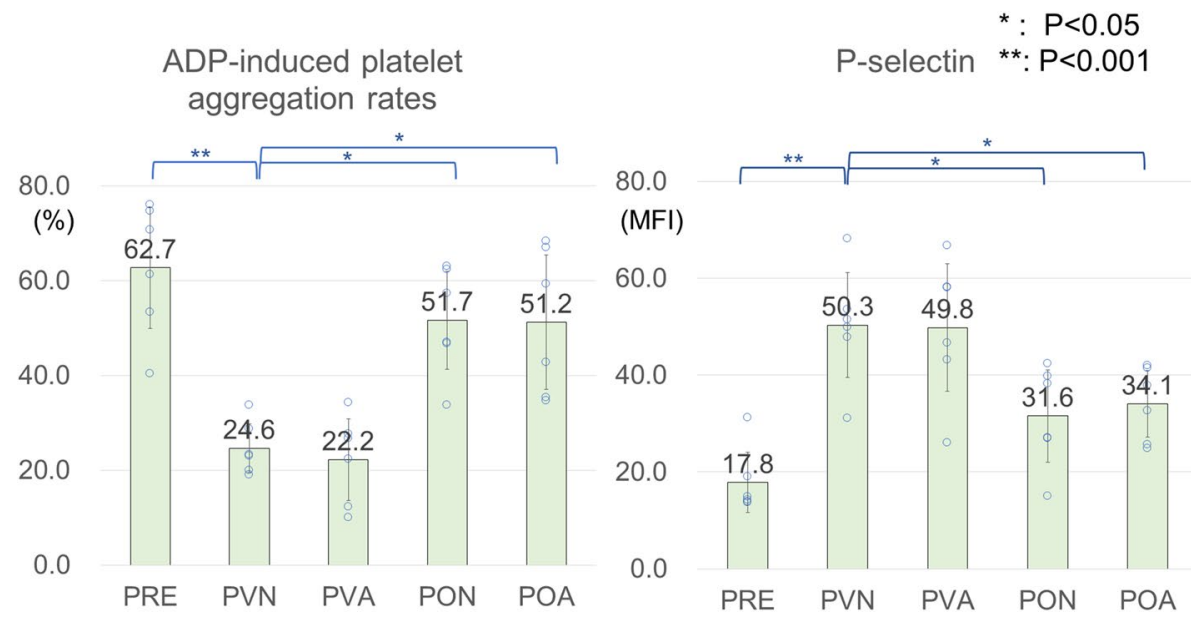

Figure 2. Comparison of ADP-induced platelet aggregation rates and P-selectin results. Compared to PRE, ADP-induced platelet aggregation rates in PVN and PVA storage decreased significantly and P-selectin expression of PVN and PVA increased significantly. Whole blood storage in polyolefin bags (PON and POA) maintained twofold higher ADP-induced platelet aggregation rates and a significantly lower P-selectin expression compared to PVN. ${ }^{\star} \mathrm{P}<0.05,{ }^{*} \mathrm{P}<0.001$ vs. PVN by one-way ANOVA with a Dunnett multiple comparison test.

\section{Discussion}

In this study, we showed that whole blood storage in a polyolefin bag maintained higher ADP-induced platelet aggregation rates and lower P-selectin expression, compared to the conventional method used in ANH (Table 2 and Fig. 2). The decrease in aggregation rate measured by light transmittance aggregometry correlates with the amount of bleeding ${ }^{26,27}$. P-selectin (CD62P) is a membrane protein present in a granules of platelets, and its expression level on the unstimulated platelet surface is a common measure of platelet activations ${ }^{28}$. Platelets stored in the container are affected by various factors including duration of storage, temperature, $\mathrm{pH}$, solution, gas permeability of the container for $\mathrm{O}_{2}$ and $\mathrm{CO}_{2}$ and interruption of agitation ${ }^{29}$. The platelet injuries associated with extracorporeal storage are called platelet storage lesions (PSLs) ${ }^{30}$, which lead to platelet activation via the necrotic and apoptotic processes, resulting the reduction of survival in vivo and hemostatic activity after 
transfusion ${ }^{29}$. Thus, decline of agonist-induced aggregation rates, P-selectin expression, morphological change and increased lactate level are the major manifestations of PSLs. ANH using polyolefin bags is advantageous in reducing PSLs and improving hemostatic function over the conventional method.

Some studies have shown that platelet function of whole blood stored in blood bags markedly decreases and does not recover after transfusion in ANH. Ramnarine et al. showed that collagen-induced formation of large stable hemostatic aggregates (platelet macroaggregation) were markedly decreased to $29.4 \%$ after collecting blood into a CPDA bag and to $14.7 \%$ after 80 min of storage, compared to that before the collection, and that this deterioration was largely irreversible by the reinfusion of $\mathrm{ANH}^{12}$. Scott et al. showed that blood in bag storage with CPDA for $300 \mathrm{~min}$ had significantly reduced platelet function, as measured by thrombin receptor activating peptide stimulation in multiple electrode aggregometry (Multiplate) analysis and maximum clot formation on ROTEM EXTEM ${ }^{13}$. Gallandat Huet et al. showed platelet aggregation response measured by Multiplate in ex-vivo stored blood with heparin decreased compared to the pre-CPB levels ${ }^{11}$. Therefore, a new preservation method is required to maintain the platelet function in $\mathrm{ANH}$.

In our study, storage with highly gas permeable polyolefin maintained lower $\mathrm{PCO}_{2}$ and higher $\mathrm{pH}$ compared to PVN group (Table 2 and Fig. 2). Of ATP production by platelets, $85 \%$ is derived from aerobic metabolism ${ }^{24,29}$. In the 1980s, platelet concentrates were stored in PVC bags, but could not maintain the platelet function because of the accumulation of $\mathrm{CO}_{2}$ and lactate followed by a rapid decrease of $\mathrm{pH}^{31}$. Low $\mathrm{pH}$ generally causes platelet morphological change (below 6.7) and irreversible loss of viability (below 6.2) ) $^{30,32}$. The whole blood stored in PVC bags in our study also showed a significant decrease in $\mathrm{pH}$, but these declines were insufficient to cause the morphological changes. The polyolefin bags currently used for storage of platelet concentrates are 2.2 times more oxygen permeable and 3.6 times more $\mathrm{CO}_{2}$ permeable than PVC bags ${ }^{22,33}$. Use of high gas-permeable containers with gentle agitation ensures $\mathrm{O}_{2}$ and $\mathrm{CO}_{2}$ exchange between the storage medium and the atmosphere, and prevents local hypoxia resulting in lactate production ${ }^{22,24}$. This storage condition prevents PSLs and increases the ability to stop bleeding after transfusion ${ }^{22,29}$. However, it is unclear whether the gas permeability of the bag affected the aerobic metabolism of platelets in our results. Krause et al. showed that just limiting gas exchange in storage bag of platelet concentrates causes accumulation of $\mathrm{PCO}_{2}$, decreased $\mathrm{pH}$, increased lactate, and increased P-selectin expression ${ }^{34}$. Similarly, the high gas permeability of the storage bag in our study may have led to higher aggregation rates and low P-selectin expression, although the underlying biochemical pathway is unknown. Mean platelet volume of platelets generally increases inversely related to $\mathrm{pH}$, indicating a poor quality of product ${ }^{35}$, which did not change in this study. In contrast, there were no significant differences caused by agitation (Table 2 and Fig. 2, PVN-PVA, PON-POA). Thomas ${ }^{24}$ showed that interruption of agitation for several hours did not reduce platelet function. In addition to agitation, the platelet concentration and the surface area of the storage bag affect the oxygen partial pressure ${ }^{33}$. The effect of agitation on the platelet count and function may depend on the storage container, agitation speed and other conditions.

Preservative solution and temperature also influence PSLs. CPDA used in ANH is an anticoagulating solution suitable for long term storage of red blood cells in preoperative autologous blood donation ${ }^{20}$, but is not optimized for platelet storage. CPDA contains sodium citrate hydrate and dextrose, and the $\mathrm{pH}$ is $5.6-5.8$. Several studies have reported that citric acid impairs platelet function even in short-time storage as practiced in $\mathrm{ANH}^{12,36}$. Hyperglycemia can induce hyperreactivity of platelets to high shear stress and increased P-selectin within $4 \mathrm{~h}^{37,38}$. For these reasons, CPDA is not a suitable solution for storage of platelets. The recommended temperature for platelet storage has changed over time. Platelet storage at $4{ }^{\circ} \mathrm{C}$ was performed in the 1970 s, but $20-24^{\circ} \mathrm{C}$ or room temperature is currently recommended based on reports that platelets stored below $20-24{ }^{\circ} \mathrm{C}$ rapidly change irreversibly and lose their viability after transfusion ${ }^{24,32}$. Room temperature storage is also recommended in $\mathrm{ANH}$, but the temperature in the operating room during hypothermic $\mathrm{CPB}$ often falls below $20^{\circ} \mathrm{C}$, which may impair platelet function. However, some reports have indicated that cold-stored platelets contribute effectively to hemostasis ${ }^{30,39}$ and the US Food and Drug Administration recently approved cold-stored platelets in resuscitation of patients with active bleeding ${ }^{40}$. Therefore, we are planning the next study to clarify the appropriate preservative solutions and temperature for ANH, which provide better platelet function and reduce perioperative blood loss.

Red blood cell storage lesions are measured with indicators of hemolysis and the ability to deliver oxygen. There were no significant changes in hemoglobin concentration in all groups in this study. In general, severalhours whole blood storage at room temperature does not cause unacceptable injury to red blood cell functions $\mathrm{s}^{41}$; 6-h whole blood storage at $20^{\circ} \mathrm{C}$ with CPD decreases $2.3-\mathrm{DPG}$ to $88 \%$, which is acceptable ${ }^{42}$. Low pH suppresses the activity of glycolysis system, which in turn reduces 2,3-DPG required to supply oxygen to peripheral tissues and ATP production required to maintain erythrocyte morphology ${ }^{43}$, but 2,3-DPG and ATP levels recover in 7-72 h after transfusion ${ }^{43}$. High oxygen concentrations may confer oxidative stress, but the appropriate concentration range has not been determined ${ }^{23,43}$. Blood storage in polyolefin bags for several weeks are associated with greater red blood cells hemolysis compared to the storage in di-2-ethylhexil phthalate PVC bags ${ }^{17}$, but storage for several hours in our study had no effect. Mean corpuscular volume, a parameter of the erythrocyte morphology and storage lesions, tends to increase during storage ${ }^{44,45}$, but this also did not increase in our study. Red blood cells can be stored for a longer period than platelets, and the storage conditions such as higher $\mathrm{PO}_{2}$ for several hours may not affect their function ${ }^{44,46}$.

There are several limitations of this study. First, in order to reduce the burden on the volunteers, the amount of sample blood per bag was set at $20 \mathrm{~mL}$, which is much less than the recommended capacity. Therefore, the surface area, internal pressure and effect of agitation in our storage bags might not be the same as those in clinical use. Storage with small amounts will allow easier agitation and gas exchange. Our results should be supplemented by full volume experiments in the future. Second, in addition to the material and gas permeability, the different surface structures and plasticizers between the two bags used may have influenced the results. Other products may have different effects on blood cells, because the structures of blood bag varies from manufacturer to manufacturer ${ }^{16}$. Third, ANH also improves CPB-induced coagulopathy ${ }^{47}$, but the effects of storage 


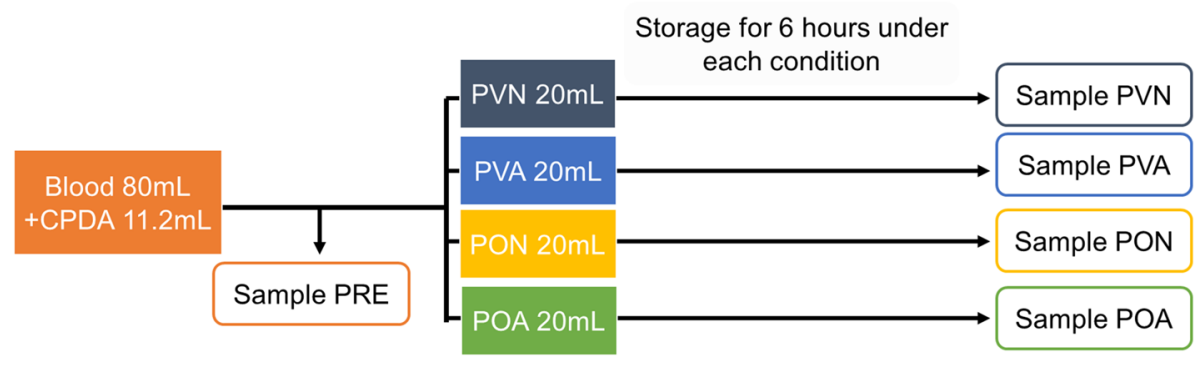

\begin{tabular}{l}
\multicolumn{2}{c|}{ Tests for each sample } \\
$\checkmark$ Complete blood count \\
$\checkmark$ Blood gas analysis \\
$\checkmark$ Measurement of ADP-induced platelet aggregation rates \\
$\checkmark$ Flow cytometry analysis of P-selectin \\
\hline
\end{tabular}

Figure 3. Flow chart of the study. Each venous blood sample from healthy volunteers was mixed with CPDA gently. After removed of a small amount of blood for tests (sample PRE), the rest of blood was divided for storage under each condition (PVN, PVA, PON, POA). After storage for $6 \mathrm{~h}$ under each condition, we tested them. This figure was drawn using Microsoft PowerPoint 2016 (Ver. 2103, https://www.microsoft.com/ja-jp/ microsoft-365/powerpoint).

conditions of ANH on coagulation factors were not examined. Coagulation factors, even the most affected factor VIII, are maintained at more than $70 \%$, which is sufficient for hemostasis, in 24 -h whole blood storage at room temperature ${ }^{48}$. Global hemostasis assay such as thromboelastography or rotational thromboelastometry should be considered as an additional functional assay. Fourth, as this study was performed in vitro, the hemostatic effect and survival time and hemolysis in vivo of stored platelets could not be evaluated. Within these limitations, our results show that whole blood stored in a polyolefin bag for $6 \mathrm{~h}$ maintains significantly higher platelet function compared to the conventional method of storage in a PVC bag, while agitation had no effect on the results.

\section{Methods}

The study was approved by the ethics committee of Kyoto University Hospital (R0978-1) and carried out according to the guidelines of the Declaration of Helsinki. All methods were performed in accordance with the institutional guidelines and regulations. Prior written informed consent was obtained from subjects. A study flow chart is shown in Fig. 3.

Storage groups. Four storage methods were examined: at rest in a PVC bag, as in conventional ANH (PVN); agitation in a PVC bag (PVA); at rest in a polyolefin bag (PON); and agitation in a polyolefin bag (POA). A Karmi CA (200 mL single, Kawasumi Laboratories, Inc., Tokyo, Japan) made of polyvinyl chloride including di-2-ethylhexyl phthalate plasticizer and containing CPDA solution was used as the PVC bag. A Kawasumi Separation bag PO (1000 mL single. Kawasumi Laboratories) made of polyolefin without any plasticizer and anticoagulant was used as the polyolefin bag. The $\mathrm{O}_{2}$ permeabilities of the PVC and polyolefin bags are $1.10 \pm 0.04$ and $2.37 \pm 0.30 \mathrm{nmol} / \mathrm{min} / \mathrm{atm} / \mathrm{cm}^{2}$ and the $\mathrm{CO}_{2}$ permeabilities are $9.8 \pm 0.5$ and $35.43 \pm 6.8 \mathrm{nmol} / \mathrm{min} / \mathrm{atm} / \mathrm{cm}^{2}$, respectively ${ }^{33}$. CPDA solution was removed from the PVC bag, and the volume of each PVC and polyolefin bag was adjusted to $20 \mathrm{~mL}$ by rolling the bag up and fixed with metal clips. A horizontal rotatory agitator (Labo Shaker BC-740, Bio Craft, Inc, Tokyo, Japan) was used for agitation at $60 \mathrm{rpm}$.

Chemicals and drugs. ADP was purchased from Nacalai Tesque (Kyoto, Japan). Peridinin chlorophyll protein (PerCP)-labeled anti-CD61 antibody, and phycoerythrin (PE)-labeled anti-CD62P (P-selectin) antibody were obtained from Becton Dickinson (San Diego, CA, USA). The composition of CPDA removed from a PVC bag was citric acid hydrate $0.327 \mathrm{w} / \mathrm{v} \%$, sodium citrate hydrate $2.630 \mathrm{w} / \mathrm{v} \%$, monobasic sodium phosphate 0.251 $\mathrm{w} / \mathrm{v} \%$, dextrose $2.900 \mathrm{w} / \mathrm{v} \%$ and adenine $0.0275 \mathrm{w} / \mathrm{v} \%$. The $\mathrm{pH}$ was $5.6-5.8$. All other chemicals were of analytical grade. It was confirmed that all buffers and solvents used for dilution had no effects on the results.

Blood collection and storage. A sample of $80 \mathrm{~mL}$ of venous blood was collected by venipuncture of forearm veins from 6 healthy volunteers who had not taken any medication for at least two weeks before blood sampling. The blood was mixed with $11.2 \mathrm{~mL}$ of CPDA ( $8.14 \mathrm{v} / \mathrm{v} \%$; the percentage specified for use of PVC bags currently used in ANH) gently. After removal of $11 \mathrm{~mL}$ of blood for testing (sample PRE), the rest of the blood was divided into $20 \mathrm{~mL}$ volumes for each of the four groups. The blood was injected into 4 bags and extra air was removed. PVN and PON bags were set at rest, while PVA and POA bags were placed on a horizontal rotatory agitator at $60 \mathrm{rpm}$, with all 4 bags stored at $22^{\circ} \mathrm{C}$ in an incubator box for $6 \mathrm{~h}$. After storage, the blood was agitated gently and tested (samples PVN, PVA, PON, POA). 
Complete blood count and blood gas analysis. Each sample (PRE, PVN, PVA, PON, POA) was tested promptly after collection using the following methods. Complete blood counts and blood gas parameters were measured using an automated hematology analyzer (Celltac a Nihon Kohden, Tokyo, Japan) and an automated blood gas analyzer (RAPIDPoint 500 or RAPIDLab 1265 Siemens Healthineers, Munich, Germany).

Measurement of ADP-induced platelet aggregation rates. Platelet-rich plasma (PRP) was prepared by centrifugation of a blood sample at $160 \mathrm{~g}$ for $10 \mathrm{~min}$ at room temperature, followed by collection of the supernatant. The remaining lower portion was further centrifuged at $1600 \mathrm{~g}$ for $15 \mathrm{~min}$ at room temperature and the clear supernatant was used as platelet-poor plasma (PPP). The platelet count was adjusted to $3 \times 10^{5} / \mu \mathrm{L}$ by dilution with PPP (adjusted PRP). Aggregation induced by ADP was measured with a light transmission aggregometer (MCM Hema Tracer 212; MC Medical, Tokyo, Japan). Adjusted PRP $\left(3 \times 10^{5} / \mu \mathrm{L}, 200 \mu \mathrm{L}\right)$ was pipetted into a cylindrical cuvette and incubated at $37^{\circ} \mathrm{C}$ for $3 \mathrm{~min}$, and then the adjusted PRP was stirred at $37^{\circ} \mathrm{C}$ with a magnetic bar at $1000 \mathrm{rpm}$. A $10-\mu \mathrm{L}$ volume of $200 \mu \mathrm{M}$ ADP (final concentration: $9.5 \mu \mathrm{M}$ ) was added to the cylindrical cuvette and ADP-induced platelet aggregation rates was measured for $10 \mathrm{~min}$ as a change in light transmission from that of PPP, which was taken to be $100 \%$.

Flow cytometry analysis of P-selectin. Flow cytometry was performed as we have described previously ${ }^{49,50}$. Adjusted PRP was diluted tenfold with phosphate-buffered saline (PBS) ( $\mathrm{pH} 7.42$ ) containing $139 \mathrm{mM} \mathrm{NaCl}, 8.1 \mathrm{mM} \mathrm{NaHPO}_{4}, 1.5 \mathrm{mM} \mathrm{KH}_{2} \mathrm{PO}_{4}$, and $2.7 \mathrm{mM} \mathrm{KCl}$. Samples were fixed with ice-cold $1 \%$ formaldehyde for at least $60 \mathrm{~min}$ in a refrigerator and washed twice with ice-cold PBS by centrifugation at $1600 \mathrm{~g}$ for $15 \mathrm{~min}$ at $4{ }^{\circ} \mathrm{C}$. The pellet was suspended in $100 \mu \mathrm{L}$ PBS at $4{ }^{\circ} \mathrm{C} .20 \mu \mathrm{L}$ of the suspension was coincubated with PerCP-labeled anti-CD61 antibody and PE-labeled anti-CD62P (P-selectin) antibody in a final volume of $100 \mu \mathrm{L}$ adjusted with PBS for $60 \mathrm{~min}$ at room temperature in the dark. PE-labeled IgG was used to estimate nonspecific binding. The reaction was stopped by adding ice-cold PBS. Samples were analyzed using a fluorescence-activated cell sorting instrument (FACSCalibur Becton Dickinson, San Jose, CA, USA). For each sample, data from 10,000 platelets were collected. Platelets were identified by forward and side scatter intensity and by CD61 expression. P-selectin levels on activated platelet surface membranes were recorded as the mean fluorescent intensity (MFI) of PE.

Statistical analysis. All data are expressed as a mean (standard deviation: SD) of 6 experiments. Group variances were tested by a Brown-Forsythe test and were statistically equal. All data were compared by oneway ANOVA, followed by a Dunnett test compared to PVN. All analyses were performed using JMP Pro 15.10 (https://www.jmp.com/ja_jp/software/predictive-analytics-software.html) (SAS Institute Inc., Cary, NC, USA) with $P<0.05$ considered significant.

Received: 6 March 2021; Accepted: 31 May 2021

Published online: 09 June 2021

\section{References}

1. Shander, A. et al. Standards and best practice for acute normovolemic hemodilution: Evidence-based consensus recommendations. J. Cardiothorac. Vasc. Anesth. 34, 1755-1760 (2020).

2. Ferraris, V. A., Davenport, D. L., Saha, S. P., Austin, P. C. \& Zwischenberger, J. B. Surgical outcomes and transfusion of minimal amounts of blood in the operating room. Arch. Surg. 147, 49-55 (2012).

3. Roberts, N., James, S., Delaney, M. \& Fitzmaurice, C. The global need and availability of blood products: A modelling study. Lancet. Haematol. 6, e606-e615 (2019).

4. Ellingson, K. D. et al. Continued decline in blood collection and transfusion in the United States-2015. Transfusion 57, 1588-1598 (2017).

5. Barile, L. et al. Acute normovolemic hemodilution reduces allogeneic red blood cell transfusion in cardiac surgery: A systematic review and meta-analysis of randomized trials. Anesth. Analg. 124, 743-752 (2017).

6. Zhou, X., Zhang, C., Wang, Y., Yu, L. \& Yan, M. Preoperative acute normovolemic hemodilution for minimizing allogeneic blood transfusion: A meta-analysis. Anesth. Analg. 121, 1443-1455 (2015).

7. Goldberg, J. et al. Greater volume of acute normovolemic hemodilution may aid in reducing blood transfusions after cardiac surgery. Ann. Thorac. Surg. 100, 1581-1587 (2015).

8. Ferraris, V. A. et al. Perioperative blood transfusion and blood conservation in cardiac surgery: the society of thoracic surgeons and the society of cardiovascular anesthesiologists clinical practice guideline. Ann. Thorac. Surg. 83, S27-S86 (2007).

9. Ortmann, E. et al. Point-of-care assessment of hypothermia and protamine-induced platelet dysfunction with multiple electrode aggregometry (Multiplate) in patients undergoing cardiopulmonary bypass. Anesth. Analg. 116, 533-540 (2013).

10. Kotake, Y. et al. Platelet dysfunction during cardiopulmonary bypass assessed by a novel whole-blood aggregometer. J. Cardiothorac. Vasc. Anesth. 20, 536-540 (2006).

11. Gallandat Huet, R. C. G., de Vries, A. J., Cernak, V. \& Lisman, T. Platelet function in stored heparinised autologous blood is not superior to in patient platelet function during routine cardiopulmonary bypass. PLoS One 7, 1-4 (2012).

12. Ramnarine, I. R. et al. Autologous blood transfusion for cardiopulmonary bypass: Effects of storage conditions on platelet function. J. Cardiothorac. Vasc. Anesth. 20, 541-547 (2006).

13. Scott, K. J., Shteamer, J. W., Szlam, F. \& Sniecinski, R. M. Platelet function, but not thrombin generation, is impaired in acute normovolemic hemodilution (ANH) blood. J. Clin. Anesth. 58, 39-43 (2019).

14. Reyher, C. et al. Einfluss der akuten normovolämischen hämodilution auf die primäre hämostase. Anaesthesist 63, 496-502 (2014).

15. Storch, E. K., Custer, B. S., Jacobs, M. R., Menitove, J. E. \& Mintz, P. D. Review of current transfusion therapy and blood banking practices. Blood Rev. 38, 100593 (2019).

16. Prowse, C. V. et al. Commercially available blood storage containers. Vox Sang. 106, 1-13 (2014).

17. Hill, H. R., Oliver, C. K., Lippert, L. E., Greenwalt, T. J. \& Hess, J. R. The effects of polyvinyl chloride and polyolefin blood bags on red blood cells stored in a new additive solution. Vox Sang. 81, 161-166 (2001).

18. Robinson, S. et al. The administration of blood components: A British Society for Haematology Guideline. Transfus. Med. 28, 3-21 (2018). 
19. Udani, D., Porecha, M., Mehta, S., Vaghela, M. \& Doshi, D. A comparative study of autologous versus homologous blood transfusion during general surgery. Internet J. Surg. 19, 1-6 (2008).

20. Thomas, M. J. G., Gillon, J. \& Desmond, M. J. Preoperative autologous donation. Transfusion 36, 633-639 (1996).

21. Vanderlinde, E. S., Heal, J. M. \& Blumberg, N. Autologous transfusion. BMJ 324, 772-775 (2002).

22. Van der Meer, P. F. \& de Korte, D. Platelet preservation: Agitation and containers. Transfus. Apher. Sci. 44, 297-304 (2011).

23. Antonelou, M. H. \& Seghatchian, J. Insights into red blood cell storage lesion: Toward a new appreciation. Transfus. Apher. Sci. 55, 292-301 (2016).

24. Thomas, S. Platelets: Handle with care. Transfus. Med. 26, 330-338 (2016)

25. Singh, V., Gupta, P. \& Khatana, S. Blood gas analysis for bedside diagnosis. Natl. J. Maxillofac. Surg. 4, 136 (2013).

26. Jin, L. et al. The prognostic value of ADP-induced platelet aggregation for bleeding complications in low-Intermediate risk patients with acute coronary syndrome taking clopidogrel after percutaneous coronary intervention. Hear. Lung Circ. 26, 49-57 (2017).

27. Adeli, E. K., Alavi, S. M., Alizadeh-ghavidel, A., Bakhshandeh-Abkenar, H. \& Pourfathollah, A. A. Perioperative changes in platelet count and function in patients undergoing cardiac surgery. Med. J. Islam. Repub. Iran. 10, 31-37 (2017).

28. Dumont, L. J., VandenBroeke, T. \& Ault, K. A. Platelet surface P-selectin measurements in platelet preparations: An international collaborative study. Transfus. Med. Rev. 13, 31-42 (1999).

29. Ohto, H. \& Nollet, K. E. Overview on platelet preservation: Better controls over storage lesion. Transfus. Apher. Sci. 44, 321-325 (2011).

30. Seghatchian, J. \& Krailabsiri, P. The platelet storage lesion. Transfus. Med. Rev. 11, 130-144 (1997).

31. Murphy, S. et al. Improved storage of platelets for transfusion in a new container. Blood 60, 194-200 (1982).

32. Holme, S. Storage and quality assessment of platelets. Vox Sang. 74(Suppl 2), 207-216 (1998).

33. Torres, R. \& Tormey, C. A. Modelling gas exchange during platelet storage without agitation. Vox Sang. 111, 445-448 (2016).

34. Krause, M., Doescher, A., Zimmermann, B. \& Müller, T. H. Noninvasive pH measurement to monitor changes during suboptimal storage of platelet concentrates. Transfusion 50, 2185-2192 (2010).

35. Singh, H., Chaudhary, R. \& Ray, V. Platelet indices as quality markers of platelet concentrates during storage. Clin. Lab. Haematol. 25, 307-310 (2003).

36. Wallén, N. H., Ladjevardi, M., Albert, J. \& Bröijersén, A. Influence of different anticoagulants on platelet aggregation in whole blood; A comparison between citrate, low molecular mass heparin and hirudin. Thromb. Res. 87, 151-157 (1997).

37. Gaiz, A., Mosawy, S., Colson, N. \& Singh, I. Thrombotic and cardiovascular risks in type two diabetes; Role of platelet hyperactivity. Biomed. Pharmacother. 94, 679-686 (2017).

38. Gresele, P. et al. Acute, short-term hyperglycemia enhances shear stress-induced platelet activation in patients with Type II diabetes mellitus. J. Am. Coll. Cardiol. 41, 1013-1020 (2003).

39. Valeri, C. R. Circulation and hemostatic effectiveness of platelets stored at $4 \mathrm{C}$ or $22 \mathrm{C}$ : Studies in aspirin-treated normal volunteers. Transfusion 16, 20-23 (1976).

40. Stubbs, J. R. et al. Cold platelets for trauma-associated bleeding: Regulatory approval, accreditation approval, and practice implementation-Just the "tip of the iceberg". Transfusion 57, 2836-2844 (2017).

41. Thomas, S. Ambient overnight hold of whole blood prior to the manufacture of blood components. Transfus. Med. 20, 361-368 (2010).

42. Knutson, F., Lööf, H. \& Högman, C. F. Pre-separation storage of whole blood: The effect of temperature on red cell 2,3-diphosphoglycerate and myeloperoxidase in plasma. Transfus. Sci. 21, 111-115 (1999).

43. Yoshida, T., Prudent, M. \& D’Alessandro, A. Red blood cell storage lesion: Causes and potential clinical consequences. Blood Transfus. 17, 27-52 (2019).

44. Ghezelbash, B. et al. Comparative evaluation of biochemical and hematological parameters of pre-storage leukoreduction during RBC storage. Int. J. Hematol. Stem Cell Res. 12, 35-42 (2018).

45. Kim, S. J., Lee, E. Y., Song, Y. J. \& Song, J. The instability of commercial control materials in quality control of mean corpuscular volume. Clin. Chim. Acta 434, 11-15 (2014).

46. Yoshida, T., AuBuchon, J. P., Tryzelaar, L., Foster, K. Y. \& Bitensky, M. W. Extended storage of red blood cells under anaerobic conditions. Vox Sang. 92, 22-31 (2007).

47. Suzuki, R. et al. Effect of autotransfusion using intraoperative predonated autologous blood on coagulopathy during thoracic aortic surgery: A randomized controlled trial. Ann. Thorac. Cardiovasc. Surg. 25, 311-317 (2019).

48. Cardigan, R. et al. Coagulation factor content of plasma produced from whole blood stored for 24 hours at ambient temperature: Results from an international multicenter BEST Collaborative study. Transfusion 51, 50S-57S (2011).

49. Murata, Y., Kawamoto, S. \& Fukuda, K. Rocuronium has a suppressive effect on platelet function via the P2Y12 receptor pathway in vitro that is not reversed by sugammadex. Int. J. Med. Sci. 21, 1-10 (2020).

50. Kawamoto, S., Hirakata, H., Sugita, N. \& Fukuda, K. Bidirectional effects of dexmedetomidine on human platelet functions in vitro. Eur. J. Pharmacol. 766, 122-128 (2015).

\section{Acknowledgements}

This work was supported by Grant-in-Aid for Scientific Research (KAKENHI), Grant Number 19K18293.

\section{Author contributions}

Y.M. and E.K.: data collection, data analysis, and drafting of the paper. S.K.: study conception and design, interpretation of data, and revision of the manuscript. K.F.: supervising the study and revision of the manuscript. All authors have approved the final version of the paper.

\section{Competing interests}

The authors declare no competing interests.

\section{Additional information}

Correspondence and requests for materials should be addressed to S.K.

Reprints and permissions information is available at www.nature.com/reprints.

Publisher's note Springer Nature remains neutral with regard to jurisdictional claims in published maps and institutional affiliations. 
(c) (i) Open Access This article is licensed under a Creative Commons Attribution 4.0 International cc) License, which permits use, sharing, adaptation, distribution and reproduction in any medium or format, as long as you give appropriate credit to the original author(s) and the source, provide a link to the Creative Commons licence, and indicate if changes were made. The images or other third party material in this article are included in the article's Creative Commons licence, unless indicated otherwise in a credit line to the material. If material is not included in the article's Creative Commons licence and your intended use is not permitted by statutory regulation or exceeds the permitted use, you will need to obtain permission directly from the copyright holder. To view a copy of this licence, visit http://creativecommons.org/licenses/by/4.0/.

(C) The Author(s) 2021 